\author{
Abstracta Iranica \\ Abstracta Iranica Revue bibliographique pour le domaine irano-aryen \\ Volume 37-38-39 | 2018 \\ Comptes rendus des publications de 2014-2016
}

\title{
Michele Minardi. "A silver rhyton from Afghanistan held in the Cleveland Museum of Art and its historical context"
}

\section{Julien Cuny}

\section{(2) OpenEdition Journals}

Édition électronique

URL : http://journals.openedition.org/abstractairanica/47347

DOI : 10.4000/abstractairanica. 47347

ISBN : 1961-960X

ISSN : 1961-960X

Éditeur :

CNRS (UMR 7528 Mondes iraniens et indiens), Éditions de l'IFRI

\section{Référence électronique}

Julien Cuny, « Michele Minardi. "A silver rhyton from Afghanistan held in the Cleveland Museum of Art and its historical context" », Abstracta Iranica [En ligne], Volume 37-38-39 | 2018, document 12, mis en ligne le 30 décembre 2018, consulté le 28 septembre 2020. URL : http://journals.openedition.org/ abstractairanica/47347 ; DOI : https://doi.org/10.4000/abstractairanica.47347

Ce document a été généré automatiquement le 28 septembre 2020.

Tous droits réservés 


\title{
Michele Minardi. "A silver rhyton from Afghanistan held in the Cleveland Museum of Art and its historical context"
}

\author{
Julien Cuny
}

\section{RÉFÉRENCE}

Michele Minardi. "A silver rhyton from Afghanistan held in the Cleveland Museum of Art and its historical context", Journal Asiatique 303, 2015, p. 59-86

1 L'exceptionnel rhyton en argent du musée de Cleveland est composé de deux parties assemblées: une tête féminine surmontant une tête de buffle d'eau indien. Une inscription en pehlevi incisée sur la nuque du personnage féminin indique son poids. Il avait fait l'objet de plusieurs études, en particulier de la part de D. Shepherd en 1966 puis de M. Carter en 1979, qui avaient proposé d'y voir respectivement une production sogdienne du $\mathrm{V}^{\mathrm{e}}-\mathrm{VI}^{\mathrm{e}}$ siècle, ou d'Afghanistan de la fin du VII $\mathrm{s}$.

Considérant à nouveau la datation d'œuvres d'un style comparable, notamment de stucs de sites bouddhiques, l'A. appuie la thèse d'une production gandharienne mêlée d'influences de l'art Gupta dont les premières pénétrations au Gandhara sont sensibles à partir du $\mathrm{V}^{\mathrm{e}} \mathrm{s}$. apr. J.-C. La tête de buffle au contraire trouve ses meilleurs parallèles dans la toreutique thrace et est-méditerranéenne d'époque hellénistique ancienne et l'A. n'y reconnaît pas, contrairement à l'interprétation de Shepherd, les traces d'une stylisation linéaire caractéristique des productions iraniennes. Pour expliquer une telle persistance de modèles hellénistiques (et des techniques associées), l'A. suppose l'existence et la transmission de modèles (emblemata) similaires à celui du $\mathrm{I}^{\mathrm{er}} \mathrm{s}$. apr. J.-C., en gypse, trouvé dans le trésor de Bégram et remontant à des prototypes alexandrins du III ${ }^{\mathrm{e}}$ s. av. J.-C., une pratique également connue au Gandhara pour la fabrication de 
sculptures en stuc. La tête de buffle serait ainsi l'un des plus récents témoignages de la persistance au Gandhara de cette " manière » méditerranéenne.

Reprenant enfin à son compte les liens qu'avait décelés R. Göbl en 1987 entre l'iconographie de ce rhyton et le monnayage des rois de Nezak, désormais mieux daté, l'A. en fait plus précisément une production de la première moitié du $\mathrm{VI}^{\mathrm{e}} \mathrm{s}$. dans la région de Kaboul et Ghazni, où ces rois ont régné. L'A. veut donc y voir un objet ayant appartenu à l'un d'eux ou à un membre de leur cour.

\section{AUTEURS}

JULIEN CUNY

Conservateur au Musée du Louvre, Paris 